\title{
Effect of Foot Reflexology on Stress and Anxiety during Pregnancy
}

\author{
EMAN S.A. EL-FEKEY, M.Sc.*; HALA M.H. OMARA, Ph.D.**; GHADA E. EL-REFAYE, Ph.D.** and \\ MOHAMED F.M. ABOU EL-ENIN, M.D.*** \\ The Department of Women's Health, Medical National Institute, Damanhour*, the Department of Women's Health, \\ Faculty of Physical Therapy, Cairo University** and the Department of Obstetrics \& Gynecology, Om El-Masryeen Hospital***, \\ Giza
}

\begin{abstract}
Background: Pregnancy is a period of great stress to a woman both physically and mentally. There is a varied prevalence of pregnancy anxiety at different trimesters of pregnancy with high levels in first and third trimesters.

Aim of the Study: This study was conducted to determine effect of foot reflexology on stress and anxiety during pregnancy.

Patients and Methods: Fifty pregnant women diagnosed clinically by gynecologist/physician as primigravida at their third trimester, they were selected from Outpatient Clinic of Obstetrics and Gynecology in Damanhour Medical National Institute suffering from anxiety based on psychiatric assessment. Their age ranged from 20 to 30 years. Their Body Mass Index (BMI) $<-30 \mathrm{~kg} / \mathrm{m}^{2}$. They were assigned randomly into two Groups (A,B) equal in numbers. Group (A) received diaphragmatic breathing exercise, 5-10 minutes, 3-4 times per day for 6 weeks. While, Group (B) received diaphragmatic breathing exercise plus reflexology on pressure points in feet for 30 minutes per session, 3 times/week for 6 weeks. Stress and anxiety were evaluated by blood pressure, pulse rate and Hamilton anxiety rating scale before and after the intervention.

Results: There was a highly statistical significant decrease in median value of Hamilton anxiety scale of study Group (B) when compared with its corresponding value in control Group (A) with $p$-value $=0.001$.
\end{abstract}

Conclusion: These results suggested that the foot reflexology was very effective method in improving stress and anxiety during pregnancy.

Key Words: Pregnancy anxiety - Stress - Nulliparous women - Fear of childbirth - Reflexology.

\section{Introduction}

STUDIES suggest that a significant portion of pregnant women have prenatal anxiety, generally and regarding their pregnancy. Recent studies estimated a $29 \%$ prevalence of antenatal anxiety among pregnant women [1].

Correspondence to: Dr. Eman S.A. El-Fekey, Medical National Institute, Damanhour
Pregnancy-specific anxiety is defined as worries, concerns and fears about pregnancy, childbirth, and health of infant and future parenting [2]

Anxiety during pregnancy is associated with a shorter gestation and lower birth weight, with consequences for infant development [3].

The fetal heart rate, the activity, sleep patterns and movements, all indicators of neurobehavioral development, are significantly affected by maternal stress, depression, and anxiety [4].

Because of the cultural and socioeconomic environment in various developing regions of the world, sex discrimination and the preference for sons rather than daughters may contribute to anxiety among pregnant women [5]

Reflexology is believed to trace back to the ancient people of Asia, who realized the many benefits of strategic touch as part of a healing therapy routine. Some evidence indicates that ancient Egyptians also practiced this type of healing therapy. Treating the body through the feet and hands has also been found in many indigenous healing systems. For example, Native Americans and Australian aborigines are both believed to have healing practices based on foot manipulation [6] .

Several reasons could be proposed as an effect for reflexology, which is touching skin can cause the release of endogenous endorphins of the body and would reduce the stress; therefore, with stress reduction, the pain would consequently reduce and the opposite is also true. The second reason is that reflexology can remove the fatigue and anxiety. A third cause, explain that applying pressure on hands or feet activate large diameter fibers to close the pain gate, thereby inhibit the transmission of pain [7]. 


\section{Patients and Methods}

Fifty pregnant women were suffering from stress and anxiety based on psychiatric assessment. They were assigned randomly into two Groups (A, B) equal in numbers. Group (A) received diaphragmatic breathing exercise, 5-10 minutes, 3-4 times per day for 6 weeks. While, Group (B) received diaphragmatic breathing exercise plus reflexology on pressure points in feet for 30 minutes per session, 3 times/week for 6 weeks. The inclusion criteria were as follow: Primigravida at their third trimester, their age ranged between 20-30 years and their BMI was $\leq 30 \mathrm{~kg} / \mathrm{m}^{2}$. The exclusion criteria were as follow: Multiparous women, infection disease or fever, foot ulcers, foot infection or undergoing foot surgery, recent fracture in foot and toes with unhealed wounds, thrombotic disease of lower extremities, deep proprioception loss, peripheral neuropathy and gout or advanced arthritis affecting the foot and toes. The women participated in the study after signing an informed consent form before data collection. After ethical approval, pregnant women were selected from outpatient clinic of obstetrics and gynecology in Damanhour Medical National Institute, Beheira, Egypt. The study was conducted from January 2017 to July 2017. The subjects' characteristics are shown in (Table 1).

Table (1): Physical characteristics of all participants in both Groups (A \& B).

\begin{tabular}{lcccc}
\hline & $\begin{array}{c}\text { Group (A) } \\
(\mathrm{n}=25)\end{array}$ & $\begin{array}{c}\text { Group (B) } \\
(\mathrm{n}=25)\end{array}$ & $\begin{array}{c}t \text { - } \\
\text { value }\end{array}$ & $\begin{array}{c}p \text { - } \\
\text { value }\end{array}$ \\
\hline Age (yrs. $)$ & $25.76 \pm 2.47$ & $24.44 \pm 2.49$ & 1.883 & $0.066(\mathrm{NS})$ \\
Weight (Kg.) & $74.12 \pm 4.53$ & $74.02 \pm 6.69$ & 0.062 & $0.951(\mathrm{NS})$ \\
Height (cm.) & $161.88 \pm 3.06$ & $161.84 \pm 5.58$ & 0.031 & $0.975(\mathrm{NS})$ \\
BMI $\left(\mathrm{kg} / \mathrm{m}^{2}\right)$ & $28.26 \pm 1.19$ & $28.25 \pm 1.69$ & 0.026 & $0.980(\mathrm{NS})$ \\
\hline
\end{tabular}

Data are expressed as mean \pm SD.

NS: $p>0.05$ : Not Significant.

\section{Material:}

- Hamilton anxiety rating scale was used to measure anxiety.

-Weight-height scale was used to measure weight and height of each pregnant woman to calculate BMI before starting this study.

- Plinth for the patient to long site or lie.

- Pillows to support head of patients.

- Chair for the therapist.

- Disposable plastic clean gloves.

- Alcohol and some cotton to clean area before the treatment.
- The treatment performed in quiet and air conditional room.

\section{Procedures:}

- All women were given a full explanation of the protocol of the study and consent form were signed for each woman before participating in the study. They were referred to the psychiatry department and the same psychiatrist asked every patient some questions (e.g. do you have difficulty falling asleep or staying asleep?) To quantify the severity of anxiety symptomology, Hamilton anxiety scale will be used for that then the psychiatrist will refer the cases of anxiety to Physical Therapy Department for application the study [8]. Blood pressure and pulse (heart rate) were measured. The assessment were before the study and after the end of 6 weeks.

- On each session before starting reflexology work the skin of the feet were inspected for position and angle of each foot; differences between feet, situation of the two feet on the couch, relationship of each toe to the others, colour variations, patches, flecks and spots of colour, textural variationsdips, swellings, etc., irregularities and infections and skin conditions. No creams, lotions or powders were used as these can interfere with the ability to assess the feet fully or to grip them adequately to perform the treatment [9] .

- Massage the foot all over slowly but firmly to loosen it up, beginning at the toes moving down towards the heel, for about thirty seconds [8]

- Applying controlled firm and even pressure, it should not hurt or tickle using the thumb for that and forefinger for holding. The basic thumb walking technique for feet will be used by alternately bend and straighten the thumb, pushing gently into the tissue as walking, repeat this until the surface of each area of the foot will be covered because 12 points must be stimulated [10]

- Reflexology steps were done according to foot chart and imagine a map of the body. The same points for anxiety on each session, these points represent zones of diaphragm, brain, heart, liver, spleen, pituitary, thymus, thyroid, kidneys, parathyroid, adrenal gland and the solar plexus area.

- Duration of reflexology will be as the following:

- 15 minutes for right foot.

- 15 minutes for left foot.

- At the subsequent appointment the practitioner should enquire about the mother's condition following the first treatment, recording any reactions, side effects, concerns, improvements or deterio- 
rations in her general wellbeing. This will enable the therapist to make any necessary adaptations to the treatment and form the basis for ongoing care [9].

\section{Results}

The results of this study revealed that there was a highly statistical significant decrease in median value of Hamilton anxiety scale of study Group (B) when compared with its corresponding value in control Group (A) with $p$-value $=0.001$.

The results of this study confirmed that there was a highly statistically significant decrease in stress and anxiety in the study Group (B) who treated with foot reflexology and diaphragmatic breathing compared with the degree of stress and anxiety in control Group (A) who received diaphragmatic breathing only. The results of this study are showed in Fig. (1).

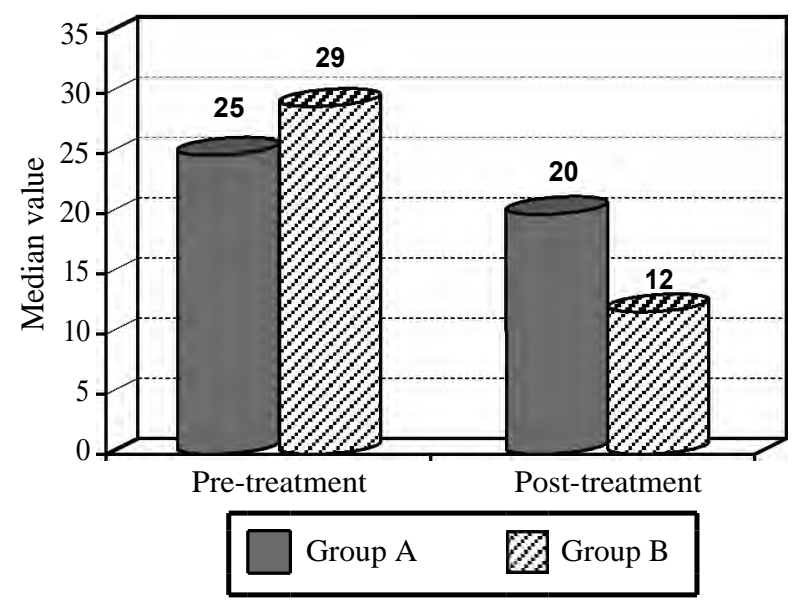

Fig. (1): Comparison between median values of Hamilton anxiety rating scale (HAM-A) in both Groups (A \& B) measured pre-and post-treatment.

\section{Discussion}

The results of this study confirmed that stress and anxiety respond well to foot reflexology during pregnancy. These results agreed with Samir et al., [11], who determined the effectiveness of foot reflexology on anxiety of patients undergoing hemodialysis. The results of this study indicated that foot reflexology is effective to reduce the level of anxiety among hemodialysis patients. The experimental group received foot reflexology twice in a week for 3 consecutive weeks and each session lasted for 20 minutes where a control group followed hospital routine management. The data were collected by structured questionnaire. The mean post-test anxiety score in the experimental group was 16.6 , and in the control group, it was 22.55 , which was significantly greater. The $t$-test value was 3.50 and was found significant at $p<0.001$ level. The values revealed that there was a statistically significant difference in a level of anxiety between the experimental and control groups in the post-test. The study results show that the foot reflexology was effective to reduce the level of anxiety.

The results of this study agreed with those of Arash et al., [12], who investigate the effects of foot reflexology on physiological parameters of patients before coronary angiography. In the intervention group for 30 minutes of foot reflexology massage and stimulate the soles of the feet in three points the solar plexus, the pituitary gland and the heart was performed, the results of this study that the positive effect of foot reflexology on blood pressure and reduces the amounts used. But no have positive effect on heart rate and respiratory rate. Foot reflexology to reduce blood pressure in patients before angiography, which can be caused by things like stress, fear of the unknown procedure and the procedures.

The results of this study are supported by Jang and Kim [13], who showed that self-foot reflexology was effective in reducing perceived stress and fatigue and helped blood circulation in premenopausal middle-aged women.

The results of this study agreed with Mc Vicar et al., [14], who confirmed that reflexology had a powerful anxiety-reduction effect ('state'; $p<0.001$ ) but no significant effect on underlying anxiety ('trait'). Cardiovascular parameters decreased $(p<0.001)$. Baseline salivary cortisol and melatonin were not significantly correlated with STAI scores and did not change significantly following reflexology. Reflexology reduced 'state' anxiety and cardiovascular activity within healthy individuals, consistent with stress-reduction. Considering the connection between stress/anxiety and wellbeing, the effects of reflexology may have beneficial outcomes for patients.

The result of this study agreed with those of Soheila et al., [15], who examined the effect of foot reflexology on anxiety, pain, and outcomes of the labor in primigravida women and found that anxiety decreased after using reflexology method in the intervention group, but the anxiety increased in the control group.

The current study findings are in line with Soo and Kye [16], who showed that self-foot reflexology was effective in reducing perceived stress and fatigue and helped blood circulation in premenopausal middle-aged women. Self-foot reflexology 
may be an effective nursing intervention in reducing perceived stress and fatigue and in improving blood circulation.

On the other hand the results of this study disagree with the systematic review of the efficacy of reflexology of Wang et al., [17], who found no evidence for any specific effect of reflexology in any conditions, with the exception of urinary symptoms associated with multiple sclerosis. The study concluded that routine provision of reflexology is therefore not recommended.

\section{Conclusion:}

Based on the scope and findings of this study, it could be concluded that foot reflexology are effective on pregnant women suffering from stress and anxiety during the third trimester of pregnancy.

\section{References}

1- NASREEN H.E., KABIR Z.N., FORSELL Y. and EDHBORG M.: Prevalence and associated factors of depressive and anxiety symptoms during pregnancy: A population based study in rural Bangladesh. B.M.C. Women's Health, 11 (1): 22, 2011.

2- HUIZINK A.C., MULDER E.J., ROBLESDEMEDINA P.G., VISSER G.H. and BUITELAAR J.K.: Is pregnancy anxiety a distinctive syndrome? Early Human Development, 79 (2): 81-91, 2004.

3- KINSELLA M.T. and MONK C.: Impact of maternal stress, depression and anxiety on fetal neurobehavioral development. Clin. Obstet. Gynecol., 52 (3): 425-40, 2009.

4- KINSELLA M.T. and MONK C.: Impact of maternal stress, depression \& anxiety on fetal neurobehavioral development. Clin. Obs. Gynecol., 52 (1): 1-15, 2013.

5- WAQAS A., RAZA N., LODHI H.W., MUHAMMAD Z., JAMAL M. and REHMAN A.: Psychosocial factors of antenatal anxiety and depression in Pakistan: Is social support a mediator? 10 (1): 1-14, 2015.

6- SYNTHIA A. and BOBBI D.: Acupressure and Reflexology for dummies, 1 st ed, Wiley Publishing, Inc. 111 River St. Hoboken, Indianapolis, Indiana; pp. 12-70, 2007.
7- HUGHES C.M., KRIRSNAKRIENGKRAI S., KUMAR S. and McDONOUGH S.M.: The effect of reflexology on the autonomic nervous system in healthy adults: A feasibility study. Alternative Therapy Health Med., 17 (3): 32-7, 2011

8- DARWISH E.M.: Response of anxiety to reflexology in elder, Department of physical therapy for Cardiovascular/ Respiratory Disorder \& Geriatrics, Unpublished master thesis, Faculty of Physical Therapy, Cairo University; Pp. 30-2, 2011.

9- TIRAN D.: Reflexology in Pregnancy and Childbirth, 1 st ed, Churchill Livingstone Elsevier, London, UK, Pp. 445, 2010.

10- STILLERMAN E.: Modalities for Massage and Bodywork. 1 st ed, Mosby; Pp. 129-43, 2009.

11- SAMIR K., NUTAN P., et al.: Astudy to assess effectiveness of foot reflexology on anxiety of patient undergoing hemodialysis in Tertiary care hospital, Karad, 10 (7): 3457, 2017.

12- ARASH K., NEGIN MASOUDI A., DAVOUD M., NASTOOR B.P., AKVAN P., MEHDI D., SHAPOUR Y., SABA B. and MEHDI M.V.: The effect of foot reflexology on physiological parameters. International Journal of Medical Research \& Health Sciences, 5 (9): 50-4, 2016.

13- JANG S.H. and KIM K.H.: Effects of self-foot reflexology on stress, fatigue and blood circulation in premenopausal middle-aged women. J. Korean Acad. Nurs., 39 (5): 662 72, 2009.

14- Mc VICAR A.J., GREENWOOD C.R., FEWELL F., D'ARCY V., CHANDRASEKHARAN S. \& ALLDRIDGE L.C.: Evaluation of anxiety, salivary cortisol and melatonin secretion following reflexology treatment: A pilot study in healthy individuals. Complementary Therapies in Clinical Practice, 13 (3): 37-14, 2007.

15- SOHEILA M.H., ZAHRA M.T. and MAHNAZ S.: The Effect of Foot Reflexology on Anxiety, Pain, and Outcomes of the Labor in Primigravida Women. Acta. Med. Iran, 53 (8): 507-11, 2015

16- SOO HYUN JANG and KYE HA KIM: Effects of selffoot Reflexology on Stress, fatigue and blood Circulation in premenopausal middle-aged women. Journal of Korean Academy of Nursing, 39 (5): 662-72, 2009.

17- WANG M.Y., TSAI P.S., LEE P.H., CHANG W.Y. and YANG C.M.: The efficacy of reflexology: Systematic review. J. Adv. Nurs., 62 (5): 512-20, 2008. 


\section{تآثير ريفليكسولوجى القدم على الضغط الفئ الفمل \\ والقتق النفسى آثثاء الحمهل}

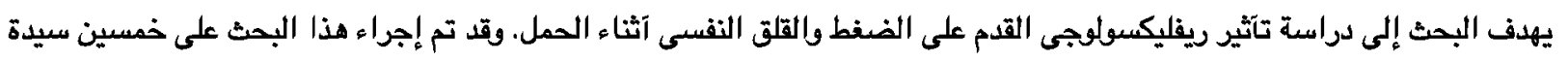

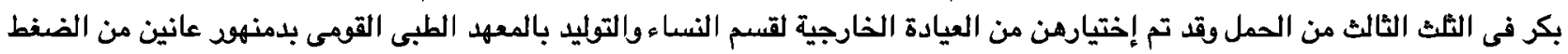

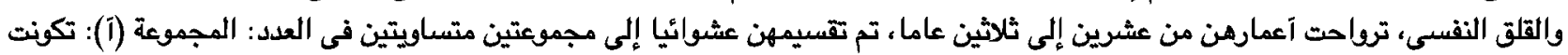

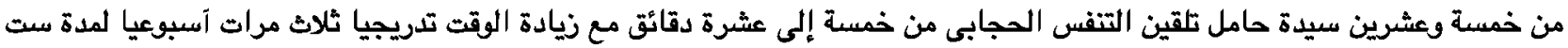

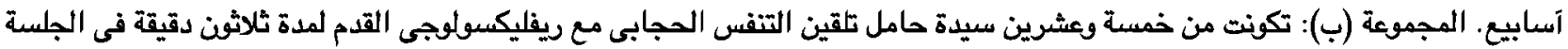

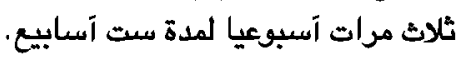

$$
\text { وقد تم تقييم المجموعتين (آ،ب) قبل وبعد العلاج عن طريق مقياس هاميلتون لتقدير مدى القلق. }
$$

النتائج: آوضحت النتائج آن هناك فروق ذات دلالة إحصائية عالية بعد العلاج بين المجموعتين (اعب). ومقارنة المجموعتين معا كان هناك

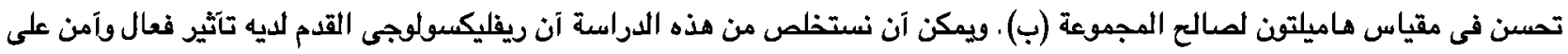
تقليل التوتر والقلق آثناء الحمل. تصاءل 